\title{
Problematic Areas Related to Sexual Life of Individuals with Gynecological Cancer: A qualitative Study in Turkey
}

\author{
Gul PINAR ${ }^{1}$, Tevfik PINAR ${ }^{2}$, Ayse AKALIN ${ }^{1}$, Tulay SAYDAM ${ }^{3}$, Ali AYHAN ${ }^{3}$ \\ ${ }^{1}$ Yildirim Beyazit University, Faculty of Health Sciences, Department of Nursing \\ ${ }^{2}$ Hacettepe University, Institute of Public Health \\ ${ }^{3}$ Tulay Saydam, RN, BSN, Baskent University, Faculty of Medicine, \\ Department of Gyne-Oncology, Ankara, TURKEY
}

\begin{abstract}
This study was conducted to examine problematic areas related to sexual life of individuals with gynecological cancer. Qualitative phenomenological research design was used in the study. The data were collected through "Semistructured In-depth Interview Form" and "Individual Information Form" with 30 women diagnosed with gynecological cancer. In-depth interview technique was used for obtaining data related to sexual problem areas of women. The data obtained were evaluated by content analysis. Average age of women who participated in the study was $46.70 \pm 10.66$ ( $\min =30, \max =67)$, and women who were followed for the diagnosis of endometrium cancer (53.3\%), ovarian cancer (36.7\%), cervical cancer (10\%). It was determined that there were significant changes in sexual lives of the individuals following the illness, and that body image, role of sexuality, sexual functions and reproduction ability, which are the four important components of sexual health, were affected unfavorably to a great extent. It was determined in this study that individuals with gynecological cancer face multidimensional problems regarding sexual life. Adoption of holistic approach by health professionals in the evaluation of sexual problems of women and attempting to solve the problem are of significance.
\end{abstract}

Keywords: Gynecological cancer, Sexual health, Qualitative study, Turkey

\section{ÖZET}

Jinekolojik Kanserli Bireylerin Cinsel Yaşama İlişkin Sorun Alanları: Türkiye’den Kalitatif Bir Çalışma

Bu çalışma jinekolojik kanserli bireylerin cinsel yaşama ilişkin sorun alanlarını incelemek amacıyla yapılmıştı. Çalışmada, niteliksel fenomenolojik bir araştırma tasarımı kullanılmıştır. Çalışmaya 30 jinekolojik kanser tanıı alan kadın katılıı̧tır. Verilerin toplanmasında; Hasta Bilgi Formu ve Yarı Yapılandırımış Derinlemesine Görüşme Formu kullanılmışıı. Soruların çözümlemesi içerik analizi yöntemiyle

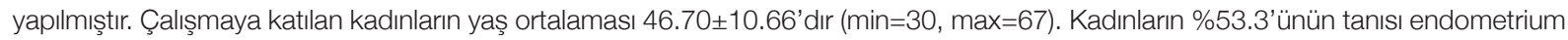
kanseri, \%36.7'sinin over kanseri ve \%10'unun ise serviks kanseridir. Bireylerin hastalık sonrası cinsel yaşamlarında önemli değişikler olduğu, cinsel sağlığın dört önemli öğesi olan beden imajl, cinsiyet rolü, cinsel fonksiyonlar ve üreme yeteneğinin büyük ölçüde olumsuz etkilendiği belirlenmiştir. Çalışmamızda jinekolojik kanserli bireylerin cinsel yaşama ilişkin çok boyutlu sorunlarla karşılaştıkları belirlenmiştir. Sağık profesyonellerinin kadınların cinsel sorunlarının değerlendirilmesinde holistik yaklaşımı benimsemeleri ve sorunun çözümü için girişimde bulunmaları önem taşımaktadır.

Anahtar Kelimeler: Jinekolojik kanser, Cinsel sağlık, Kalitatif çalışma, Türkiye 


\section{INTRODUCTION}

Today, cancer is regarded as a chronic illness that has an impact on physical, psychological and sexual life. ${ }^{1,2}$ Based on the data of GLOBOCAN published by International Agency for research on Cancer a total of 14.1 million new cancer cases developed in the world and 8.2 million deaths caused by the cancer were observed. ${ }^{3}$ It was indicated that 19.3 million new cancer cases will occur in the year 2025. The deaths caused by cancer in Turkey ranked as the second among the causes that give way to death. Gynecological cancer is observed on the top following breast cancer among women that is resulted in death and has a vital place among cancer types that are most frequently detected by women in Turkey. ${ }^{4}$

Surgical interventions, radiotherapy, chemotherapy and hormonal replacement treatments applied in gynecological cancers have impact on sexual health of women..$^{5-8}$ In the patients diagnosed with gynecological cancer, specifically four elements of sexual health are affected negatively, body image, role of sexuality, sexual functions and reproduction ability, because women reproduction organs are the determiners of female identity. ${ }^{9-10}$ Thus, ailment or absence of these organs could be interpreted as the loss of womanhood, loss of fertility, end of sexual life and may make a woman feel herself as faulty or deficient. ${ }^{6,7,9-11}$

Researches show that most of the women diagnosed with gynecological cancer experience sexual problems such as orgasmic dysfunction, dyspareunia, loss of sexual desire and decrease in sexual intercourse frequency. ${ }^{5,6,11-13}$ In our country, due to social, cultural factors and the influence on religion, sexuality is a subject that is not avoided to talk about openly and it is still regarded as a taboo. For this reason, health providers don't regard sexuality as a part of treatment and care due to their feeling of embarrassment. This makes it harder to reveal the sexual problems women diagnosed with gynecological cancer. ${ }^{10,12}$ Thus, there are not enough researches on the effects of any form of gynaecological cancer on a woman's sexuality in our country. For this reason, there is a need for studies to be focused on the effect of gynaecological cancer on sexual health for the women of varied socio-cultural and socio-economic classes in different regions. ${ }^{8-10,12-14}$ In this context, the research was conducted for the purpose of scrutinizing the problem areas of individuals with gynecological cancer regarding their sexual life.

\section{MATERIAL AND METHODS}

A qualitative phenomenological research pattern was used in the study, and it was conducted at the gynecologic oncology clinic of Baskent University between February and April 2014 in Ankara. Between these dates, the clinic of the hospital visited on 3 days of the week (Sunday, Monday and Tuesday) and interviewed women diagnosed with gynecological cancer and who agreed to participate in the study. The samples included 30 women whose age ranged between 30 and 67 years old.

The sample of study was included of women who; 1) were diagnosed with gynecological cancer (endometrial, cervical, ovarian, vaginal, vulvar and fallopian tubes cancer), 2) were sexually active and have healthy partners, 3) were over 18 years of age and volunteered for the study, 4) had no disability for making the communication difficult such as hearing and language problem, 5) had no known psychiatric ailment, 6) had undergone cancer treatment (i.e. chemotherapy, radiotherapy and surgery) at least 12 weeks ago without any complications and 7) had not had any different disorder that would have interfered with sexual function.

"The Individual Information Form" and "The Semi-constructed In-Depth Interview Form" were used by face to face interviews for data collection. The Individual Information Form generated by reviewing the literature on the matter by the researchers, a total three section were included for determining their socio-demographic (9 question), the diagnostic and therapeutic procedures (5 question), and their sexual health conditions, both before and after the disease (8 question). ${ }^{1,6,10,12,15-17}$

Semi-constructed "In-depth Interview Form" including open-ended questions was used in the study. A qualitative evaluation was made in the study about body image, sexual role, reproduction ability and sexual functions. ${ }^{9}, 10$ The interview form included open-ended questions such as 1) How did 
How did your illness and the administered treatments along with it affect your outer appearance?

Reproduction Ability

How did your illness and treatments administered for this illness affect your fertility?

Sexual Role

How did your illness, administered treatments and the process after the treatment affect you as a spouse/partner or a mother?

Sexual Function

How did the diagnosis of your illness and the administered treatments affect your sexual life when compared with the period before your illness?

your illness and the administered treatments along with it affect your outer appearance? 2) How did your illness and treatments administered for this illness affect your fertility? 3) How did your illness, administered treatments and the process after the treatment affect you as a spouse/partner or a mother? 4) How did the diagnosis of your illness and the administered treatments affect your sexual life when compared with the period before your illness? (Box 1).

In the study, it was conducted for the pre-application of the interview form by interviewing with three women and required arrangements were made in the interview form afterwards. Interviews brought together in an empty room where comfortable communication was thought to be achieved with the women when they felt ready for an interview. Semi-constructed interviews were recorded by a voice recorder device and transferred to the computer environment, listened repeatedly and turned into a written document. The interviews lasted 20-30 minutes depending on the answers of the women.

Content analysis was used in the analysis of the quality data regarding sexual problems of women. Voice recordings and notes obtained from the interviews were solved one-to-one and transferred into the qualitative data analysis program NVivo8. ${ }^{18}$ The analysis was made by means of this program. Questions included in the interviews were used as an umbrella category, and the answers given to these questions formed the sub categories. Analysis steps in the research followed the stages of reading the data in an integration taking notes of the expressions that seemed peculiar to the researcher or repeated continuously, determination of words that describe the codes, and determining the proper plots and turning them into a report.
Ethical permit was received from Baskent University Research and Ethics Committee for conducting the research. Women who participated in the research were informed about the research matter and purpose, and necessary explanations were made for them for keeping all of the information confidential according to confidentiality and privacy principles, and written and oral permits were received for the women.

\section{RESULTS}

\section{Results of Individual Characteristics}

Average age of the women was $46.70 \pm 10.66$ ( $\mathrm{min}=$ $30, \max =67)$ and average marriage age of the women was $22.17 \pm 5.12(\min =15, \max =34)$. It was determined that $26.7 \%$ were $30-39$ of age, $30 \%$ were $40-49$ of age and $43.3 \%$ of women were 50 and above age group. $36.7 \%$ were graduated from middle and high school, and $60 \%$ of the women did not work. All of women were married, three had not child, the others at least had one or more children and $56.7 \%$ of women were married out of love. When data on the illness properties of women were evaluated, it was determined that $53.3 \%$ had endometrium cancer, $36.7 \%$ had ovarian cancer, $10.0 \%$ had cervical cancer, $40.0 \%$ were in Stage II, and $76.7 \%$ had Total Abdominal Hysterectomy-Bilateral Salpingo-oophorectomy surgical operation and women received different treatments, such as surgery, chemotherapy, radiotherapy or a combination of them. Most of women (70\%) had not sexual problem before being diagnosed with gynecological cancer, but after surgery all of them experienced sexual problems. After the surgery $23.3 \%$ of women experienced painful sexual intercourse, $36.7 \%$ described herself "being an incomplete woman" and $40 \%$ of women experienced loss of libido. All of the women reported that they 
experienced sexual problems regarding body image, function of sexual role, sexual functions and reproduction ability following the illness however 93.3\% of them stated that they did not receive consultancy from health professional on this subject.

\section{Results on Body Image}

The question "How did your illness and treatment administered along with it affect your outer appearance?" was directed in the study for determining body image perception. Most of the participants expressed that themselves as incomplete women and complained about alopecia caused by chemotherapy, and unbearable pain.

One of the participants expressed that:

"I feel that I am aging because of chemotherapy and radiotherapy. I had unbearable pain and my life was interrupted, I feel like I am not living ever since I heard about the diagnosis. I feel battered, outworn and broken." (35 years of age, cervical cancer).

Another participant expressed her feelings by turning her eyes away as follow:

"I had 3 surgeries. I have stitch marks because of the surgeries. I've lost hair, gained weight, my intestines opened outwards. I used to like spending time in front of the mirror. I don't want to look at it anymore." (42 years of age, ovarian and endometrium cancer).

One of the participant expressed her feelings as follow:

"It feel like that I am aging after the treatments. I used to care so much about my appearance; I would want to look attractive for my husband. Right now, I am only thankful that I am alive." (46 years of age, ovarian and endometrium cancer).

Another participant expressed what she was going through crying as:

"I am going to lose my hair. The treatment process was very difficult. I did not have any strength during that process. I was withdrawn. I did not enjoy anything. I did not even go out for a month. I was horrible with the same socks, same slippers and pajamas and I did not want anyone see me like this." (31 years of age, ovarian cancer).
Another participant said that:

"I am happy that my illness was in my uterus, it could be in my breasts and they could be removed and discarded. I must be a good servant of God because it happened within me. It did not cause a deficiency in my body outside." (49 years of age, endometrium cancer).

A participant expressed her feelings as follow:

"I feel exhausted since I got this disease. I have difficulty in doing things I used to do before. I have started to feel useless myself. The hysterectomy operation, hair loss, and gaining weight are not so important at this age..." (61 years of age, endometrium cancer).

\section{Results on Reproduction Ability}

The question "How your illness and the treatment administered to you along with this illness affect your fertility?" was directed to the women in the study.

A married young participant expressed her feelings as:

"When I learned that I had cancer for the first time, I broke down, because I am married. We do not have the baby yet, I won't be able to make my husband a father, but I was able to say 'I come first' and gave up the child. I don't have the right to make my husband experience this, if he wants to end our marriage, I can understand him..." (30 years of age, ovarian cancer).

One of the participants expressed her feelings agitatedly as:

"My biggest sorrow is not to have child, I regret so much that I did not give birth before I got sick. I asked my husband whether he is sad that we won't have children. He said if we want it so much we will adopt one. I don't know if this is true or not. He may speak like this so he won't feel sorrow..." (30 years of age, ovarian cancer).

Another participants expressed her feelings as: "We already have a child, God let him live long. My uterus was taken and I don't have any worries to become pregnant. Now I will have more comfortable sexual relation with my husband. This is the only thought making me comfortable." (41 years of age, endometrium cancer). 
One of the participant expressed her feelings as: "When I heard about the diagnosis, I did not know how to react. My doctor told me that I needed to have surgery and it would be impossible for me to give birth after the surgery. I was not sad about this, because I have 3 children but if I didn't have any children this would be very difficult for me. I don't know how I could handle this because my children are the most valuable things that I have." (52 years of age, endometrium cancer).

An old participant expressed her feelings as:

"I think, not to be able to have children is very terrible opinion for a women. This should be asked to young people: "How do you feel?". We have children and I am not young women. Fortunately, I was diagnosed when I was younger" (65 years of age, cervical cancer).

\section{Results on Sexual Role}

In order to determine the role of being diagnosed with gynecological cancer on the sexual role in the study, the question "How did the administered treatment and the following process affect you as a woman, a spouse/partner or a mother?" was directed. Most of the participants' statement was that the role of motherhood was not much affected. However, all felt upset, since they were physically helpless towards their children because of tiredness and fatigue.

One of the participants expressed her feelings with a concerned appearance as:

"I say 'my uterus and ovaries were removed, no more menstruations' as we girl-talk, and they say 'mmm, removal of the uterus must be like not having eyes and ears, aren't you a woman any longer, are you like a man now', I have crying bursts and I receive psychiatric support, I want to feel better." (34 years of age, cervical cancer).

Another participant expressed her feelings as:

"Will my husband be able to continue to regard me as his wife? Or else would we only be friends? Following the surgery, even I started to question my womanhood. I don't know what my husband is thinking about it." (40 years of age, ovarian cancer).
Another participant expressed her feelings in tears as:

"What I am going through as a mother is very difficult. My child is too little. I cannot take care of him enough, I cannot hold him, I cannot go to bed with him. There is an infection risk. My husband is very sad too but he doesn't show it to me. There are things I need to do for my children. I need to raise them to be old enough so that they can survive when I am not around. I feel sad for them so much. I am afraid that my illness will reoccur and we will not able to be seeing one another again." (45 years of age, ovarian and endometrium cancer).

\section{Results on Sexual Function}

The question about the sexual functions was directed to the women as "How did the illness diagnosis and the administered treatments affect your sexual life when compared with your life prior to your illness?" In our study, especially young women state that they feel more dissatisfaction and inadequacy regarding the role of sexual function than older women.

One of the participants expressed her feelings anxiously as:

"It feels like I am empty inside because my uterus was removed. My husband says that he also feels like he feels empty during intercourse. My husband is very fond of sex. I am worried that he will become distant to me if I cannot satisfy him. After the surgery, I didn't have any sexual desire left. I experience sexuality as a duty for my husband." (36 years of age, cervical cancer).

Another participant expressed her feelings in irritation as:

"I am 30 years old and newly married. After the surgery, I think a lot about whether I can satisfy my husband's desires and our sexual life will end. I burst into tears; I would like to get psychiatric support." (30 years of age, ovarian cancer).

One of the participant expressed her feelings hopelessly as:

"Our sexual life is not like it used to be. I have surgery marks. I feel sad that my husband stays away from me with the fear that he will cause pain during sexual intercourse and infection and that it will make my illness worse. May be my husband 
doesn't like me anymore. I feel myself insufficient." (40 years of age, cervical cancer).

Another participant expressed her feelings as: "It's already over for us. This should be asked to young people. We don't have such things anymore. We have children and grandchildren. Still once in a while my husband thinks about that but such things are not like it used to be for us." (65 years of age, endometrium cancer).

One of the participant expressed her feelings in tears as:

"I won't be able to have children any more... I have been married for 15 years. We constantly had treatment but couldn't have any children. Until I was diagnosed with cancer, we had sexual relationship. Now he says to me you should have a rest but in fact he is staying away from me. He has not been coming home for a long time. I heard that he started to see another woman. We did not talk about it but we are going to get separated... I am losing my womanhood; I am like an infertile barren field. I don't have my husband beside me anymore..." (40 years of age, endometrium cancer).

Another participant expressed her feelings as: "Sexuality is very important for the continuation of marriage. If there is not enough sexual intercourse, a man either wants to get separated, or don't say anything but goes to other women. My organs that made me a woman have become cancerous. I don't know if my husband would want to get separated from me. Sexual intercourse is not important for me but it is not like that for men. It is a necessity for them from creation." (37 years of age, ovarian cancer).

Another of the participants expressed her feelings with a concerned appearance as:

"What is important for me is to be cured by this disease. We are already sleeping on different beds. We used to feel ashamed to talk about sexuality when we were young. Do not ask me such questions please." (67 years of age, cervical cancer).

\section{DISCUSSION}

For many women, sexuality reflects complex feelings including outer appearance, womanhood feeling, child bearing ability and ability to sustain sex- ual functions. Recently conducted studies illustrate that gynecological cancers influence sexual health of women unfavorably. ${ }^{7,10,12,19}$ Owing to illnesses and administered treatments in gynecological cancers, four important components of sexual health, namely body image, sexual role function, reproduction ability and sexual function areas suffer.,10

As a result of the illness type and administered treatments in gynecological cancers, losses of organs making up the identity of women and physical changes have significant role on body image and self-esteem of women. Furthermore, side effects of gynecological cancer treatments such as nausea, vomiting, hair loss, scars and weight changes can cause unfavorable body image in women. ${ }^{6,8,20,21} \mathrm{In}$ an investigation conducted in Germany by Hawighorst-Knapstein et al. ${ }^{22}$ it was determined that there was decrease in body image scores and initiative and self-confidence of women following surgery. In a qualitative study conducted on women with gynecological cancer by Stead et al. ${ }^{23}$ women expressed that they experience apprehension about not to look attractive to their spouses as they were before the illness following medical and surgical treatments, and they would become less attractive as a sexual partner and their sexual life would suffer. In the study of Cleary et al. ${ }^{24}$ women who were diagnosed with gynecological cancer indicated that cancer and its treatment affected their body image and self-respect negatively. Results of our study indicate that women generally complain about the symptoms such as fatigue and fear of death due to the negative prognosis of the disease as the age advanced while the young women have generally concern for their body images. In the interviews held for determining body image perception, women pointed to surgical operations as the beginning of changes in their sexual life, and expressed that they experienced fear not to be seen as a woman, not to be liked by their spouses/partners and rejection. Moreover, they stated that weight gain during the treatment process, scars formed because of operation they went through and hair loss affected their outer appearance unfavorably. In our study, one of the participants indicated that she feel herself worn out, old and deficient because of chemotherapy and radiotherapy treatment, another participant, on the other hand, stated that she did not event want to 
look in the mirror following cancer treatment and surgery and she did not want her husband to see her, and these expressions reveal the apprehension experienced about body image. Thus, it would be reasonable to claim that the outcome of study is parallel with what is stated in literature.

One of the elements of sexual health damaged in gynecological cancers is diminishment or loss of reproduction ability. The most significant role the societies give to womanhood identity is fertility, motherhood and being a spouse. Reproduction organs of women bring the persons womanhood role along with fertility and prepare girls for the future with this role. Many women perceive being a woman equivalent to have a uterus and giving birth. ${ }^{10}$ The uterus is considered a very important organ in our country, the symbol of being a woman and fertility. The disability of this organ, whatever the reason is, means "being an incomplete woman". As well as being a sexual entity, it is still considered to be the symbol of motherhood. ${ }^{12,14}$ Therefore, uterus loss is evaluated as the loss of their womanhood roles. In the study of Carter et al. ${ }^{25}$ it was determined that $35 \%$ of women who were diagnosed with gynecological cancer experienced anxiety about infertility during the treatment process. In another study, it was determined that particularly young women had more anxiety about infertility during the cancer treatment process in comparison to older women. ${ }^{26}$ Stead et al. ${ }^{23}$ determined that women who had children experienced less anxiety about organ loss and in spite of this they experienced more anxiety about the diminishment of their attractiveness. In the qualitative studies of Bruner and Boyd ${ }^{9}$ and Reis et al. ${ }^{10}$ it was determined that women with gynecological cancer experienced loss about sexuality and fertility during the treatment process and intense anxiety for losing their marriage relationships. And also, a woman of 28 with ovarian cancer expressed her feelings like this: 'I would probably not feel so sad because of the fact that my uterus was removed if I had at least one child" in the study of Reis and colleagues..$^{10} \mathrm{In}$ our study, similar to the other conducted studies, it was determined that particularly young women experienced intense anxiety about fertility. Besides, it was notable that concerns about fertility decreases in older women.
It was remarkable that one of the interviewed women described herself as an "infertile barren field" following surgical treatment. In the interviews held with women about the reason of anxiety, they expressed this anxiety as not to become a mother and therefore the thought of losing their spouse/partner in our study.

For women, sexuality is a concept including being attractive, child bearing ability and body image, in addition, including emotional, intellectual and sociocultural components. ${ }^{27}$ Therefore, problems experienced about sexual functions are extremely private, disturbing and a devastating situation for women, and can lead to emotional stress, disagreement with the spouse and divorce. Therefore, application of protective medical and surgical initiatives enabling the continuation of fertility is vital in the treatment of especially young women. . $^{811-13,16}$

Another component of sexual health in gynecological cancer that suffers is sexual role. Since women have significant role and responsibilities in the family, gynecological cancer diagnosis causes important changes in the life of both women and their family. Owing to this new situation, a process can start where roles and responsibilities within the family change, coping skills fall short, emotional breakdown and economic problems may arise. In a qualitative study conducted by Butler et al. ${ }^{28}$ on the subject, for the question of the kind of anxiety they experience as a woman, spouse/partner or mother following cancer treatment, many women answered that they have anxiety to fulfill their spouse and mother roles. In a study conducted by Reis et al. ${ }^{10}$ it was determined that the women had problems to fulfill their mother and spouse roles owing to weakness and fatigue developed depending on cancer and its treatment, and they felt intense anxiety and guilt about this matter. It is inevitable that the motherhood and wifehood roles of women with gynecologic cancer can be affected negatively. The uterus, for healthy and sexually functional woman, is of a vital importance in this country. It is the symbol of femininity, sexuality, fertility and motherhood in developing societies. ${ }^{14,29}$ In our study, similar to the other conducted studies, the participants stated that they experience inability about their womanhood and motherhood roles. At the same time, it was identified that the women ex- 
perienced intense anxiety because of the inability in these roles. Individuals with cancer can transfer their role and responsibilities to family members because of the illness, therefore family makes up the large part of social support for these persons. In this regard, it is vital that health professionals support all family members for determining and strengthening support systems of women and family and enabling continuity of these supports.

The most unfavorable effect of reproduction organ cancers is on sexual functions. The arising problems change depending on illness type, stage and administered treatments. Conducted studies illustrate that sexual dysfunction (SD) occur in $20 \%$ $100 \%$ of women diagnosed with gynecological cancer. ${ }^{30,31}$ The most prevalent SD problems observed in women following gynecological cancer is diminishment in sexual desire and decrease in libido. ${ }^{7,823}$ At the same time, problems occurring in women stemming from the illness and its treatment lead to depression and anxiety in women, and ruin sexual arousal and orgasm ability and cause dyspareunia. ${ }^{31}$ Therefore, cancer treatment process and in its aftermath, women decrease their sexual intercourse frequency with their spouses/partners or may end their sexual lives completely. ${ }^{23,32,33}$ In the qualitative study conducted by Clearly et al. ${ }^{24}$ one of the participants expressed what she feels about sexuality as "For a long time after the surgery, it was like the section of my brain about sexuality lost its function. I did not have any need for sexuality in my life at all and I did not want it in my life at all". In the study of Stead et al. ${ }^{23}$ on the other hand, one of the participants expressed what she experienced sexually following gynecological cancer surgery as "It is like I am dead waist down. I don't feel anything emotionally. It feels like someone is only whipping. My desire is completely gone, and getting used to it made me very sad". In our study, majority of the women $(70 \%)$ reported that there were no problems in their sexual life before the illness, however, all of them expressed that sexual problems started after the illness. Women interviewed by us similarly in the conducted studies expressed that when the period after cancer treatment and aftermath compared with the past, their sexual desires diminished, and they did not enjoy sexual intimacy, even they regarded sexual relation as a duty and become distant to their spouses/partners. These findings show that especially sexual desire diminished in women following gynecological cancer and its treatment. In this context, result of our study can be stated to be consistent with studies in literature. In addition, studies have identified a decrease in sexual interest and activity in old age. ${ }^{34,35}$ There are similar results indicating that as the age advanced; the anxiety over sexual problems caused by the disease diminishes in our study. For this reason, the anxieties of the elderly women who do not have fertility concern are focused on the problems in diagnosis and treatment process rather than sexual life.

One of the remarkable findings in this study is that women worried about the possibility of being deserted by their spouses/partners because of sexual problems they are experiencing. It is because for many women sexuality means complex emotions containing their outer appearance, womanhood perception, child birth ability and sustaining their functions sexually. Therefore, loss of sexuality can be perceived as a great threat. Although majority of women in this study experienced SD, only $6.7 \%$ of them expressed that they received sexual counseling service. Sexuality will continue to be an unsolved problem as long as questions are not raised comfortably and not talked about thanks to cultural and social factors and religious believes in this country and remain as taboo. ${ }^{10,33}$ Before surgery, some couples may have chosen not to be sexually active, and this must be taken into account when discussing sexual activity before and after the operation. Good communication skills, especially good listening skills, are essential if a doctor is to show empathy, respect, and nonjudgmental attitudes when discussing sexual issues with patients. Yet, in gynecologic cancer-dependent SD, necessity for professional assistance of women and their spouses augments. This counseling makes up an environment for the spouses to talk about their sexual problems at the same time. In the studies of Juroskova et al..$^{32}$ Janda et al..$^{36}$ and Ponto and Bordon $^{37}$ it was determined that women feel to receive professional information about the effect of gynecological cancer treatment on sexual health. In addition, in the studies of Ekwall et al. ${ }^{38}$, Sekse et al. ${ }^{39}$ and Cleary et al. ${ }^{24}$ it was identified that ma- 
jority of women felt to receive sexual counseling however majority of them did not receive this counseling service. Studies conducted on the matter reveal that although health professionals accept sexual health and sexual function evaluation as a vital part of women care, they are inadequate in fulfilling these roles. ${ }^{40,41}$ Yet, sexuality is a matter having psychological, social, biological and cultural dimensions and requiring a multi-disciplinary perspective and is universal. It is thought that health professionals do not find themselves sufficiently equipped to develop information, skills and behavior related to sexual problems of women and cannot talk about sexuality comfortably because of cultural taboos, and therefore they are not able to evaluate sexuality of women properly or ignore such problems.

\section{CONCLUSION}

Gynecological cancers may form a direct and indirect threat for reproduction organs of women and their functions directly, loss of reproduction ability and prevention of continuity of the progeny, bodies and body perceptions, individual identity perception and roles and responsibilities undertaken related to this perceived identity and sexuality. In our study, it was determined that approximately three out of four women experienced SD and only $6.7 \%$ sought a solution. In the qualitative interviews held, it was established that women found themselves insufficient about their body image, reproduction ability and sexual roles, which affect their sexual health, and because of this they have apprehension that their spouses/partners will leave them.

Therefore, it is vital that changes caused in gynecological cancers in women are determined by health professional and especially it is vital that awareness raising programs are executed on needs of women in sexual health matters, providing counseling on sexual health and functions, and recording and monitoring the results. In this context, it is considered that taking the existing concepts, which bring a scientific perspective to sexuality and scientific researches making contribution as guidance is significant.

\section{REFERENCES}

1. Gillbert E, Ussher JM, Perz J. Sexuality after gynaecological cancer: A review of the material, intrapsychic, and discursive aspects of treatment on women's sexual-well being. Maturitas 70: 42-57, 2011.

2. American Cancer Society (2013). Sexuality for the woman with cancer. http://www.cancer.org/acs/groups/cid/documents/ webcontent/002912-pdf.pdf (Access date: 20/07/2015)

3. World Health Organization (2012). International Agency for Research on Cancer GLOBOCAN Cancer Favet Sheet. http:// globocan.iarc.fr/Pages/fact_sheets_cancer.aspx (Access date: 15/07/2015)

4. Republic of Turkey. Ministry of Health. Public Health Agency of Turkey. Department of Cancer. Statistics of Cancer 2014. http://kanser.gov.tr/Dosya/ca_istatistik/2009kanseraporu-1. pdf (Access date: 15/07/2015)

5. Ratner ES, Foran KA, Schwartz PE, Minkin MJ. Sexuality and intimacy after gynecological cancer. Maturitas 66: 23-26, 2010.

6. Cleary V, Hegarty J. Understanding sexuality in women with gynaecological cancer. Eur J Oncol Nurs 15: 38-45, 2011.

7. Keskin G, Gümüs BA. Turkish hysterectomy and mastectomy patients - depression, body image, sexual problems and spouse relationships. Asian Pacific J Cancer Prev 12: 425432, 2011.

8. Demirtas B, Pinar G. Determination of sexual problems of Turkish patients receiving gynecologic cancer treatment: a cross-sectional study. Asian Pacific J Cancer Prev 15: $6657-$ 6663, 2014.

9. Bruner DW, Boyd CP. Assessing women's sexuality after cancer therapy: checking assumptions with the focus group technique. Cancer Nursing 22: 438-447, 1998.

10. Reis N, Beji KN, Coskun A. Quality of life and sexual functioning in gynecological cancer patients: Results from quantitative and qualitaty data. Eur J Oncol Nurs, 14: 137-146, 2010.

11. Stilos K, Doyle C, Daines P. Addressing the sexual health needs of patients with gynecologic cancers. Clin J Oncol Nurs 12: 457-463, 2008.

12. Pinar G, Okdem S, Dogan N, et al. The effects of hysterectomy on body image, self-esteem and marital adjustment in Turkish women with gynecologic cancer. Clin J Oncol Nurs 16: 99104, 2012.

13. Burns M, Costello J, Ryan-Woolley B, Davidson S. Assessing the impact of late treatment effects in cervical cancer: an exploratory study of women's sexuality. Eur J Cancer Care 16: 364-372, 2007.

14. Bal MD, Yilmaz DS, Beji KN. Sexual Health in Patients with Gynecological Cancer: A Qualitative Study, Sex Disabil 31: 8392, 2013. 
15. American Cancer Society. Cancer Facts and Figures. Atlanta, GA: American Cancer Society, 2007. https://www. cancer.org/acs/groups/content/@nho/documents/document/globalfactsandfigures2007rev2p.pdf. (Access date: 10/08/2015)

16. Alcarese FC. Addressing sexual dysfunction following radiation therapy for a gynecologic malignancy. Oncology Nursing Forum 22: 1227-123, 1995.

17. Reis N, Engin R, Ingec M, Bag. A Qualitative study: beliefs and attitudes of women abdominal hysterectomy in Turkey. Int $J$ Gynecol Cancer 18: 921-928, 2008.

18. Bazeley Pat, Jackson K. Qualitative data analysis with NVivo (2nd ed.). London, Sage, 2013.

19. Bukovic D, Silovski H, Silovski T, et al. Sexual functioning and body image of patients treated for ovarian cancer. Sex Disabil 26: 63-73, 2008

20. Fobair $\mathrm{P}$, Stewart $\mathrm{SL}$, Chang $\mathrm{S}$, et al. Body image and sexual problems in young women with breast cancer. Psycho-oncology, 15: 579-594, 2006.

21. Korfage I, Essink Bot ML, Mols F, et al. Health-related quality of life in cervical cancer survivors: a population based survey. Int J Radiat Oncol Biol Phys 73: 1501-1509, 2009.

22. Hawighorst-Knapstein S, Fusshoeller C, Franz C, et al. The impact of treatment for genital cancer on quality of life and body image-results of a prospective longitudinal 10-year study. Gynecol Oncol 94: 398-403, 2004.

23. Stead M, Fallowfield L, Selby P, Brown J. Psychosexual function and impact of gynaecology cancer. Best Pract Res Clin Obstet Gynaecol 21: 309-320, 2007.

24. Cleary V, Hegarty J, Mccahthy G. How a diagnosis of gynaecological cancer affects women's sexuality. Cancer Nurs Pract 12: 32-37, 2013.

25. Carter J, Rowland K, Chi D, et al. Gynecologic cancer treatment and the impact of cancer related infertility. Gynecol Oncol 97: 90-95, 2005

26. Camperson, C. Womens's emotional experiences with gynecological oncology. The University of Texas at Arlington. Graduate thesis, Arlington, 2009. https://uta-ir.tdl.org/utair/bitstream/handle/10106/1656/Camperson_uta_2502D_10202. pdf? sequence $=1$ \&isAllowed=y (Access date: $20 / 07 / 2015$ )

27. Greimel, ER, Winter R, Kapp KS, Haas J. Quality of life and sexual functioning after cervical cancer treatment: a long-term follow-up study. Psycho-oncology 18: 476-482, 2009.

28. Butler L, Banfreld V, Sveinson T. Coceptualizing sexual health in cancer care / commentaries / authors' response. Western J Nursing Res 20: 683-705, 1998.

29. Uskul AK, Ahmad F, Leyland NA, Stewart DE. Women's hysterectomy experiences and decision making. Women Health 38: 53-67, 2003.
30. Corney RH, Crowther ME, Everett H. Psychosexual dysfunction in women with gynaecological cancer following radical pelvic surgery. Br J Obstet Gynaecol 100: 73-78, 1993.

31. Anderson B, Lutgendorf S. Quality of life in gynecologic cancer survivors. CA Cancer J Clin 47: 218-225, 1997.

32. Juraskova I, Butow P, Robertson R, et al. Posttreatment sexual adjustment following cervical and endometrial cancer: a qualitative insight. Psycho-oncology 12: 267-279, 2003.

33. Pinar G, Kaplan S, Akalin A, et al. Evaluation of Sexual Dysfunction and Affecting Factors in Turkish Women with Gynecological Cancer. Sexuality and Disability, Vol.33, 1-14, 2015.

34. Lindau ST, Schumm LP, Laumann EO, et al. A study of sexuality and health among older adults in the United States. N Engl J Med 23: 762-774, 2007.

35. Nicolosi A, Buvat J, Glasser DB, et al. Sexual behaviour, sexual dysfunctions and related help seeking patterns in middle-aged and elderly Europeans: The global study of sexual attitudes and behaviors. World J Urol 24: 423-428, 2006.

36. Janda M, Obermair A, Cellas D, et al. Vulvar cancer patients' quality of life: a qualitative assessment. J Gynecol Cancer 14: 875-881, 2004.

37. Ponto J, Barton D. Husband's perspective of living with wives' ovarian cancer. Psycho-oncology 17: 1225-1231, 2008.

38. Ekwall E, Ternestedt BM, Sorbe B. Important aspects of health care for women with gynecologic cancer. Oncol Nurs Forum 30: 313-319, 2003.

39. Sekse RJ, Raaheim M, Blaaka G, Gjengedal E. Life beyond cancer: women's experiences 5 years after treatment for gynaecological cancer. Scand J Caring Sci 24: 799-807, 2010.

40. Takahashi M, Kai I. Sexuality after breast cancer treatment: changes and coping strategies among Japanese survivors. Soc Sci Med 61: 1278-1290, 2005.

41. Willemijn MV, Bakker RM, Kenter GG, et al. Sexual issues among cervical cancer survivors: how can we help women seek help? Psycho-oncology 24: 458-464, 2015.

\section{Correspondence}

Dr. Gul PINAR

Yıldırım Beyazıt Üniversitesi

Sağlık Bilimleri Fakültesi

Hemşirelik Bölümü

Bilkent

ANKARA / TURKEY

Tel: (+90-312) 3241501

e-mail: gpinar_1@hotmail.com 